Numerous foci of fat necrosis distal to the tumour. Striking dilatation of the main pancreatic duct to an internal circumference of $3 \mathrm{~cm}$ over a considerable length.'

\section{Histology (Professor T. Symington)}

(1) Adrenals: 'Absolutely typical of the ectopic ACTH syndrome associated with Cushing's disease. The gland is tremendously hyperplastic and consists of large hypertrophied compact cells which extend out to the capsule of the gland.

(2) Pancreas: The tumour of pancreas is a typical small-cell carcinoma similar to an oatcell carcinoma of the bronchus. This is the common type of tumour which is associated with hormone production.

(3) Pituitary: The characteristic features of the pituitary are the presence of Crooke's hyaline cells which may or may not be found in the ectopic ACTH syndrome.'

\section{Comment}

The rapid onset of symptoms, the presence of diabetes, hypertension and hypokalaemic alkalosis and the development of oedema, muscle wasting and depressive psychosis were all characteristic of the so-called ectopic ACTH syndrome. Loss of diurnal rhythm of cortisol secretion and independence of pituitary control supported this diagnosis. Because of its frequent association with this syndrome, carcinoma of the bronchus was suspected, but no evidence for its presence was discovered. Excessive obesity of the abdomen had made clinical assessment of abdominal viscera difficult and the pancreatic tumour was appreciated only after the patient had lost a good deal of weight. In such circumstances, it would seem desirable to carry out a barium meal and 'follow through' when no clue to the presence of an intrathoracic lesion is forthcoming.

In view of the clinical picture and the histological appearances of the pancreatic tumour and the adrenal cortex, the Cushing's syndrome in this patient would appear to be secondary to the carcinoma of the pancreas. Pancreatic carcinoma should be considered a possibility when search for an ectopic source of ACTH is indicated.

\section{Acknowledgments}

I am very grateful to Professor Symington, Mr. Young and Dr Wilson for their respective roles mentioned above. My special thanks are due to $\mathrm{Dr}$ T. J. Thomson, not only for his permission to publish this report, but also for his constant encouragement and invaluable help.

\section{References}

ANDERSON, E.G. (1966) Non-metatastic syndromes associated with carcinoma of the bronchus. I. The endocrine system. Hosp. Med. 1, 11.

Friedman, M., Marshall Jones, P. \& Ross, E.J. (1966 Cushing's syndrome, adrenocortical hyperactivity second $\underline{\rho}$ ary to neoplasm arising outside the pituitary-adrena $\$$ system. Quart. J. Med. 35, 193.

Hallwright, G.P., NorTh, K.A.K. \& ReID, J.D. (1964 Pigmentation and Cushing's syndrome due to malignang tumours of the pancreas. J. clin. Endocr. 24, 496.

MORRELL, M.T. (1964) Cushing's syndrome associated wit bronchial carcinoma. Postgrad. med. J. 40, 614.

O'Riordon, J.L.H., Blanshard, G.P., MoxhaM, A. NABARRO, J.D.N. (1966) Corticotrophin-secreting carcinomas. Quart. J. Med. 35, 137.

Ross, E.J. (1965) Endocrine and metabolic consequences of carcinoma of the bronchus. Proc. Roy. Soc. Med. 58, 485.

\title{
A medical emergency treated by anti-mitotic drugs
}

\author{
W. S. B. LOWRY \\ M.B., M.Sc., F.F.R. \\ Senior Registrar, Department of Medicine, \\ Royal Victoria Hospital, Belfast*
}

THIS case of malignant tumour is reported since it may be the first of its kind to present in coma and subsequently be resuscitated with chemotherapy.

\section{Case report \\ Miss E.C., a 53-year-old civil servant, was \\ *Seconded from The Northern Ireland Radiotherapy Centre.}

admitted to hospital in a confused state. Two weeks before admission she attended the surgical out-patients' department with a small lump in her neck. At that time chest X-ray and blood picture were normal and Paul Bunnell was negative. There was no further history.

On examination the patient was disorientated in time and place but not in person. Optic fundi were normal. There was no loss of power in the limbs and the deep reflexes were brisk and equal 
on both sides. Plantar reflexes were flexor and there was no neck stiffness.

There was no cyanosis, anaemia, jaundice or finger clubbing. The patient's temperature was $98^{\circ} \mathrm{F}$. There was marked glandular enlargement on both sides of the neck but no inflammation of the mouth or throat. The glands felt like rubber and were particularly large on the left side where the deep cervical chain measured $8 \times 4 \mathrm{~cm}$. There were a few smaller glands in both axillae and groins. The spleen was enlarged one finger-breadth but the liver was not palpable. Cardiovascular system: pulse regular, rate $80 /$ $\mathrm{min}$, BP $140 / 80 \mathrm{mmHg}$. The heart sounds were normal and the jugular venous pressure was not elevated. The lungs were clinically clear.

A provisional differential diagnosis at this stage included wide-spread reticulosis, tuberculosis, typhoid fever, infectious mononucleosis or a cerebrovascular accident.

Investigations: Chest X-ray normal. Blood urea $54 \mathrm{mg} / 100 \mathrm{ml}$, electrolytes normal, blood sugar $128 \mathrm{mg} / 100 \mathrm{ml}$. Hb $14 \mathrm{~g} / 100 \mathrm{ml}$. White cell count $20,000 / \mathrm{mm}^{3}$, differential normal.

\section{Treatment and progress}

Following admission the patient's level of consciousness deteriorated rapidly. In $48 \mathrm{hr}$ she was deeply unconscious and her pupils widely dilated and no longer reacting to light. An emergency biopsy excision of a supraclavicular lumph gland was made. The glands were found to be gelatinous rather than caseous. Frozen section showed a highly malignant tumour, probably a reticulosis.

Since the patient was obviously about to expire the following drugs were given as an emergency measure in one intravenous injection:

$200 \mathrm{mg}$ cyclophosphamide.

$10 \mathrm{mg}$ vinblastine.

$100 \mathrm{mg}$ hydrocortisone.
This was followed by $100 \mathrm{mg}$ cyclophosphamide intravenously daily and $100 \mathrm{mg}$ hydrocortisone intramuscularly 6-hourly for 10 days.

There was a remarkable response to treatment: after a few hours the level of consciousness improved. In $48 \mathrm{hr}$ the patient was fully conscious. After 3 days she was sitting up reading newspapers. On examination after 5 days there were no enlarged lymph glands palpable in any site and her spleen was no longer palpable. After 10 days the patient was fully ambulant and the blood count was normal. She walked out of hospital 14 days later.

\section{Discussion}

The detailed histological report later showed that the case was one of reticulum-cell sarcoma. The lymph node was completely destroyed and replaced by sheets of abnormal mitotic reticulum cells. Clinically the short history and rapid growth indicated that the tumour was highly malignant. Moreover since the tumour was obviously widespread there was no indication for radiotherapy. In any case the patient was unfit to move. However, it is often precisely these highly malignant lesions that are the most radiosensitive. Since most anti-mitotic drugs are essentially radio-mimetic the dramatic response in this case is not really surprising. At the same time it should be remembered that radiosensitivity and radiocurability are two different things. Hence the ultimate prognosis with such an aggressive tumour may well be poor.

\section{Acknowledgment}

I should like to thank Professor Graham Bull and Dr A. H. G. Love for their friendly interest and help with this case. 